\title{
Fostering Visibility, Commitment and Trust on Digital Platforms: Insights into Personal Engagement Platforms from the DACH Region
}

\author{
Lisa Lohrenz \\ TU Braunschweig \\ 1.lohrenz@tu- \\ braunschweig.de
}

\author{
Simon Michalke \\ Jacobs University Bremen \\ s.michalke@jacobs- \\ university.de
}

\author{
Susanne Robra-Bissantz \\ TU Braunschweig \\ s.robra-bissantz@,tu- \\ braunschweig.de
}

\author{
Christoph Lattemann \\ Jacobs University Bremen \\ c.lattemann@,jacobs- \\ university.de
}

\begin{abstract}
Engagement platforms (EPS) are an essential technology to enable modern co-creation and service innovation. Therefore, the design of these platforms is receiving increasing attention in research. In this study, we thus conducted expert interviews with founders, CEOs, and managers of 14 personal and household-related service platform companies from the DACH region, to gain insights into their activities and mechanisms for creating and maintaining successful EPs. Drawing from a preceding literature analysis, we offer a categorization according to the four categories: easing the entry, identifying mutual needs and problems, supporting co-creation, and facilitating service innovation. In addition, the data analysis found that the measures and activities carried out by platform owners are motivated by three concepts: trust, commitment and visibility. Overall, 29 mechanisms were identified, which aid in designing EPs. Thereby, both scholars and practitioners are presented with actionable knowledge to advance their EP endeavors.
\end{abstract}

\section{Introduction}

Driven by digitalization and servitization, organizations engage in collaborative practices to provide more innovative offerings to please customers who seek steadily growing standards of quality, comfort and personalization [6, 23]. In such collaborations heterogenous actors, such as firms, customers, partners, and other stakeholders, co-create value, and innovate services to improve the service experience of one or multiple actors [29]. Thus, traditional customer and provider roles that depict producer/consumer relationships are outdated as services may only realize their value when the offerings are actually engaged upon [42]. Following the fundamental ideas of a new service (dominant) logic, heterogeneous actors form service ecosystems in which they offer and benefit from collaboratively co-created services [29]. These service ecosystems, i.e., "relatively self-contained self-adjusting systems of resource-integrating actors connected by shared institutional arrangements and mutual value creation through service exchange" [42], rely heavily on information technology (IT) to successfully exchange information and to provide and innovate their service offerings [23].

In this context, digital platforms have been identified as being particularly well suited to foster service innovation and co-creation [3, 29]. However, there exist several, vague conceptualizations of digital platforms in literature [1]. To provide more conceptual clarity, we adopt the term engagement platform (EP) as the related literature strain and focus on actors' interactions on platforms. Breidbach et al. [9] define an EP as "physical or virtual touch point designed to provide structural support for the exchange and integration of resources, and thereby co-creation of value, between actors in a service (eco)system" ( $p$. 594). Google, for example, established several EPs to control the customer's experience in a vast EP landscape by providing both physical (Chrome book) and virtual touchpoints (e.g., Google Play Store) [13].

Establishing EPs to foster actor integration and collaboration, creates participating actors with competitive advantages by driving efficient sourcing, resource integration, and the increased absorption of firms' external knowledge that drives (more usercentered) innovation [18, 21]. With EPs becoming increasingly present across all sectors, some platform owners (PO) of EPs struggle to compete in this rapidly growing but relatively new domain that remains to be unraveled for businesses and academic scholars [34]. 
The challenges result from complex stakeholder structures, the interdependency of technological, social and organizational aspects, as well as networkrelated issues, such as the chicken-egg-problem or balancing openness and lock-in mechanism [1, 24, 41]. The complexity related to designing EPs was addressed recently by various scholars that adopted design science research as a methodology to propose design requirements and principles for EP design (e.g.[5, 20]).

Based on a comprehensive literature review we derived four categories, namely (1) easing the entry, (2) identifying mutual needs and problems, (3) supporting co-creation, and (4) facilitating service innovation for successful EP design [13]. In the paper at hand, we further evaluate and advance our preceding research by conducting 14 semi-structured interviews with experts of EPs that offer personal or household-related services. This sector was chosen as it provides an interesting case due to the inherent mix of physical and digital touchpoints of the offerings. As services in this sector affect customers more intimately, the EPs need to be especially aware of actor preferences, privacy concerns and establishing trust [27]. While these are universal factors for designing EPs, we argue that this sector needs special attention as demographic change and digitalization pose essential challenges with societal consequences [16]. Therefore, we aim to identify activities and mechanisms that improve the interaction on EPs in this context by answering the following research question: Which activities and mechanisms enable and foster interaction and innovation on EPs?

The remainder of this paper is structured as follows: First, we outline and link the theoretical concepts of service logic and EPs followed by the description of our methodological approach, before presenting our results. Finally, we conclude this paper by discussing our findings and giving an outlook on which topics to focus on in future.

\section{Theoretical background}

In recent years EPs have become an emerging topic in service and co-creation research (e.g. [7, 15]). As the term digital platforms lacks conceptual clarity and is used in a wide variety of fields, we adopt the conceptualization of EP in this paper. EPs act as mediators among the actors in service ecosystems that enhance the exchange, the provision and commercialization of resources and services [4, 17, 29]. The success of EPs is therefore directly reliant on its ability to allow and enhance value co-creation (i.e., the process in which diverse actors integrate resources for their mutual benefit), and service innovation (i.e., the improvement of service experience related to value co-creation processes) [29]. Service innovation may result in new or novel services as well as the incremental improvement of existing offerings. Thus, the service logic is a natural fit when considering value co-creation processes on EPs [5, 20, 23].

In line with the suggestion from Ojasalo and Ojasalo [31], we refer to "service logic" as an umbrella term for basic concepts of the service-dominant logic [42], service logic [21] and customer-dominant logic [25] which are tightly interwoven and inherently focused on the concept of customer value. The actors that engage in value co-creation on EPs include: customers, service providers, customer communities and corporate networks with distinctive needs and resources [14]. Yet, with a growing number of heterogeneous EPs, actors and their distinctive needs (e.g. autonomy or well-being), developing and sustaining successful EPs, is becoming increasingly complex [5]. The key challenge, therefore, lies not necessarily in developing the technological architecture but instead in governing a heterogeneous group of actors within an interrelated ecosystem striving to address constant external and internal change [36].

To vitalize co-creation activities on EPs, different ways of organizing users to reach innovation opportunities (structural flexibility) as well as mechanisms to understand and design user interactions in a network (structural integrity) need to be considered [29]. This effort, however, requires close attention to how individuals within the ecosystem are influenced by its structural properties [14]. Consequently, the EP design should be based on co-creative efforts involving heterogeneous actors [28].

To realize these competitive advantages, a critical mass of actors has to be attracted and linked on the EP [40]. As EPs are usually home to two or more distinctive actor groups (e.g. suppliers and buyers) an initial and potentially persisting challenge of balancing and growing an actor base with complementary or rivaling interests exists [19]. To identify and categorize design requirements regarding this challenge, we conducted an extensive literature review. In this review, we identified 20 design requirements for EP design. Based on these 20 requirements four design categories were derived that provide an overview of essential success factors for EP: (1) easing the entry, (2) identifying mutual problems and needs, (3) supporting value co-creation and (4) facilitating service innovation [15]. These categories address a number of activities and challenges already established in platform literature. 
Easing the entry encompasses activities that support a continued influx of new actors e.g. by lowering the barriers to adopt to existing processes and cultures [20] and collaboratively developed pricing and cost mechanisms that remain fair throughout the existence of the ecosystem, thereby ensuring a motivating environment for established and new actors on the EP [5]. Yet, lowering the costs of entry may also result in low switching costs, thus encouraging multihoming or actors switching to other EPs [24].

As the information and opportunities on the EP remain dynamic due to the everchanging external and internal environment, identifying mutual problems and needs provides EPs with more strategic and aligned direction. Effective and efficient resource allocation and mobilization to drive service innovation on the EP are improved by e.g. utilizing information technology to identify and initiate co-creation and service innovation opportunities or by involving parties not yet included in the service ecosystem of the EP [5, 20].

As stated earlier, supporting co-creation is a central property of an EP. Consequently, EPs are supposed to establish processual and institutional structures that improve the exchange of services [5]. Activities and mechanisms to improve co-creation include: involving external actors and communities to improve the density of co-creation on EPs [5, 23], coordinating of interaction, and providing freedom to (collaboratively) introduce new and improved offerings among heterogenous actors [2]. While the support of value co-creation in the service ecosystems that utilize EPs is essential [20], attracting and maintaining a critical mass of actors, relies on the ability to introduce new, as well as to improve the existing, offerings, and the overall service experience [8]. Therefore, facilitating service innovation (i.e. the improvement of the service experience) e.g. by establishing shared innovation processes [20] and providing co-design opportunities with customers and third parties is essential to the long-term success of EPs $[2,5,39]$.

This being said, facilitating service innovation is essential, as new rivalling platforms might benefit from low switching costs and technological advances and thus exert pressure on incumbent platforms to improve the service experience for actors $[18,24]$. This affects innovation platforms (that provide products and technologies that third-party provider may utilize to develop their own offerings e.g. Google Android), but also on transaction platforms (that enhance the interaction of two or more actor groups) and hybrids that combine the two types $[12,18,19$, 44]. That being said, improving the EP relies heavily on actor input $[11,24,32]$.
In face of the central challenges and design categories for EPs, the Service Logic provides an appropriate lens to reflect and discuss co-creation and service innovation activities [5, 29]. Hence this research sets out to further identify related activities and mechanisms to enable and foster service ecosystems on EPs. To unveil such activities, we conducted and analyzed 14 expert interviews which are further described in the following section.

\section{Methodology}

Due to the rapidly changing nature of EP design and the lack of previous research we conducted 14 expert interviews with POs of EPs from the personal and household-related sector. To ensure that the interviewees are qualified we interviewed either founders, CEOs, or managers of two-sided B2C transaction platforms, in the personal service sector, that have existed for at least two years.

\begin{tabular}{ll} 
Platform (Focus) & Position \\
\hline Animus (Living Quarters) & Bus. Dev. Mgr \\
Care (Childcare) & New Bus. Mgr. \\
\hline Einkaufshelden (Local Shopping) & Founder \\
ExtraSauber (Cleaning Services) & Founder \\
\hline Homesitter-Eu (House Sitting) & Founder \\
\hline Jobruf (Consumer Services C2C) & Founder \\
\hline MyFeelix (Finance and Insurance) & Sales Manager \\
MyHammer (Craftsman Services) & CEO \\
\hline MyHelpBuddy (Multi-lingual Assist) & Founder \\
\hline Nebenan (Neighborhood Activities) & Founder \\
Notfallmamas (Childcare) & Founder \\
Pengueen (Collaboration Activities) & CEO \\
\hline Sandkasten (Student Initiatives) & Founder \\
\hline Yoopies (Childcare) & Sales Manager \\
\hline
\end{tabular}

Table 1. Interview partners

For the selection of qualified candidates, a list of 136 relevant EPs with active communities in the $\mathrm{DACH}$ region (Germany (D), Austria (A) and Switzerland $(\mathrm{CH})$ ) was composed based on publicly available data. In May 2020, within a two-week selection phase, 14 companies agreed to give interviews that lasted on average 52 minutes. Subtracting 21 undeliverable mails, the response rate was $13 \%$. Participants are on average 40 years old, with three female and eleven male experts. The interviews were conducted via phone and video conference tools. All pre-scheduled interviews have been conducted and analyzed. 
An interview guideline was developed based on existing design requirements and principles for digital service platforms [15] in order to validate these and identify underlying activities and mechanisms. Semistructured interviews were chosen to give the interviewees enough freedom to elaborate. The interview questions were aimed at enhancing or solidifying the identified categories of the literature analysis [15]. Furthermore, the method should also ensure that all relevant aspects were captured and in regard to the coding process, answers were at least in parts comparable. The interview guideline consisted of five parts: (1) introduction of the interviewee and basic information of the company, (2) elaboration of functional aspects and actor constellations on the platform, (3) elaboration of interaction and value cocreation activities, (4) elaboration of service innovation processes, approaches and actor engagement and (5) elaboration of additional platform design aspects.

The interviews were conducted between 7th and 26th May 2020. Afterwards, they were transcribed and coded in MAXQDA 2020. Prior to the first expert interview an initial list of deductive codes consisted of the four categories derived from the literature analysis, i.e. "easing the entry", "mutual problems and needs", "co-creation" and "service innovation" [15]. Since several coding cycles are needed for analyzing qualitative data [35] the coding was conducted in three cycles, going from general labeling to categorization. The coding was done independently by the authors and afterwards discussed collaboratively to improve the robustness of our findings. In the first coding cycle, we used the four categories as labels. After becoming familiar with the data, we established more specific codes and subcodes in the second inductive coding cycle. We opted for inductive coding, because it allowed us to better reflect the statements of experts without being restricted only by theoretical literature [38]. For example, "Facilitating Service Innovation" got subdivided into subcodes like "Facilitation of CoDesign Activities" or "Improved Discovery of Innovation Opportunities". Thereby, in addition to the initial set of labels, 34 codes were created inductively with 382 codings, in total. These codings included the activities and mechanisms mentioned by the POs, which we later analyzed and grouped in the results section. In the evaluation of the 14 interviews, saturation was reached after 12 interviews as no additional information and codes were found. In this phase, we repeatedly encountered patterns that ran through the four initial categories investigated. It became apparent that trust, commitment and visibility were the basic concepts by which the activities and mechanism of the EPs could be further classified.
Therefore, in the third and last cycle of coding, the specific codes and subcodes of the second cycle were grouped in the four design categories derived from the literature analysis and the three concepts trust, commitment and visibility, which resulted as patterns from the inductive coding.

\section{Results}

Based on the four categories (1) easing the entry, (2) identifying mutual problems and needs, (3) supporting value co-creation and (4) facilitating service innovation, we will present 29 activities and mechanisms that have been mentioned by the POs. To increase clarity, these inputs coming directly from the experts are printed in italic. In the respective subsections, we will also outline how the fundamental concepts trust, commitment and visibility are motivating the respective activities and mechanisms. Even though a clear categorization is intended, an activity may fall into several categories, which is depicted in brackets in table 2 .

\subsection{Easing the entry}

An EP needs a critical mass of users to provide support and sustain value co-creation activities and create a competitive advantage that attracts additional actors. In order to foster a steady influx of new actors, who provide and demand offerings, POs employ various mechanisms to attract and bind actors to foster resource integration. As a result, POs need to increase the visibility of the focal EP among potential actors. Therefore, POs instrumentalize existing social media platforms, physical events, marketing campaigns, and $B 2 B$ partners to increase their awareness. While this comes as no surprise, the initial service experience of actors, especially in the personal and householdrelated service sector, needs to be deliberately crafted to the expectations of users and relies on establishing a near-immediate trustworthy relationship with the actor. This starts with many activities related to attractive features and practices that increase usability and accessibility, based on both virtual and real-world components. Virtual components are developed with a strong emphasis on easy-to-use interfaces, the availability of common payment methods, FAQs, video tutorials and other helpful resources, thereby reducing initial reluctance factors. Real-world components include training, regular visits, the attendance of actor conferences and socializing events, etc. As mentioned, all EPs provide online material to ensure user literacy. Yet some POs, like Care, Nebenan, and Animus, also provide physical welcome packages, books with exceptional examples of actors/offerings or free 
commercial material for actors to build a stronger relationship, acknowledging the physical aspects of personal and household-related services.

These activities support that new actors are introduced to the EP's rules, processes, and shared worldviews. By initially supporting and enforcing how interaction among actors is supposed to be, POs provide new actors with a shared fundamental understanding. Thereby, coordination and orientation costs of all interactions are reduced.

To ensure long-term relationships with actors, fair risk-based pricing and cost mechanisms are fundamental factors that POs define and refine collaboratively with the actors to establish mutual trust and long-lasting relationships. Therefore, all POs employ rulesets that are meant to prevent misconduct and provide binding quality standards by defining what the services include or exclude. Also, Einkaufshelden, ExtraSauber, and Care deliberately discuss and communicate their understanding of the $E P$ with new and central actors in face-to-face settings to establish a shared understanding of its properties. An explicitly formulated and shared understanding lowers the necessary costs and efforts of new actors that join EPs.

The final hurdle to attract and bind actors to EPs, especially in the context of personal and householdrelated services, is trust. EP related to services like childcare and household services conduct thorough testing of new applicants to prevent the spread of unwanted advertisement, fraud, and other abusive behavior that, in this context, are connected to extreme risks, and may quickly shatter long built trust. Therefore, POs check legal documents such as IDs, business licenses and criminal records, and conduct interviews as well as verification calls. To further increase the trust in their practices, some POs, like e.g. Care, restrict themselves only to fundamental metrics that greatly limit their analysis of on-platform activities, but strongly signal that they do not track and monetize user data.

Another approach to solidify the trustworthiness is to harness existing actor relationships and welcome new actors through corporate partners, employer contracts, and white-label solutions. E.g. one interviewee stated that they "...rather rely on established companies that have already built up trust." And that it presented a big challenge "...to establish a company, which has no name yet." These practices are common among the EPs and were often adopted after initially focusing on building a consumer base by attracting private households/consumers. As a result, the contractual relationships yielded a more solid actor base that trusted the EP, due to existing ties to their former service provider, employer, business partner or, in general terms, the already known brand.

\subsection{Identifying mutual problems and needs}

In order to solidify the overall competitive position of an EP in ever-changing markets, mutual problems and needs of actors require a constant assessment to address internal and external stimuli. The collaborative identification of these factors decreases misguided resource allocation and innovation activities on the EP, while increasing the transparency and awareness of latent capabilities among actors as well as a common understanding and direction for future developments.

This being said, the majority of EPs in our interview sample do not orchestrate strategic initiatives to sense and address mutual problems and needs collaboratively. This is especially evident for IT-based sensing of needs and problems that across all EPs is limited to the analysis of clickstream data exclusively considered for user experience optimization and activity reports. While optimization and analyzing trends are undeniably important, these IT-supported activities are limited in observing the big picture. Therefore, POs actively engage key actors to observe and implement new initiatives. In order to attract more actors to their EP, POs attend and host networking events, to receive first-hand feedback and identify internal and external stimuli. This enabled e.g. both Yoopies and ExtraSauber early on, to identify that there is a large interest to decrease undeclared work in the household service sector. By addressing this issue, they secured non-monetary support by the government and attracted companies and institutions affected by this issue to join their EPs.

With trends, problems and needs of heterogeneous actors quickly appearing and changing, all POs adopted agile development approaches to implement new features as quickly as possible so actors, that rely on changes of the technological infrastructure, can react to stimuli swiftly. This is especially important as actors otherwise might feel restricted by the POs in adopting new and adapting existing offerings. By involving them and implementing changes fast, trust in a long-term relationship with the EP is promoted and the actors are more motivated to engage in lasting and recurring value co-creation and service innovation.

\subsection{Supporting value co-creation}

To enhance resource integration among heterogeneous actors, the PO needs to consider their relationships and resource integration processes. 
Addressing them appropriately requires including actors in design processes, so the EP is catered to their interests. Consequently, all POs reported different codesign activities and mechanisms to include the actors' preferences and internal knowledge for better cocreation processes, such as e.g. Yoopies, has integrated the invoicing through co-designing on the EP.

As a result of these input and idea accumulating activities, our interviewees stated that actors provide a great influx of creative ideas for the EP. For instance, at Sandkasten, the actors can actively ask for support to help with the implementation of an idea and white label platforms, e.g. MyFeelix and Animus might implement individual solutions for some actors that are also improving resource integration/value cocreation for others. One PO stated that "it is really all users who are driving this ideas\} forward. As we are an agile project, we don't have a fixed feature set... and everything that is reported back to us ends up in the roadmap. With an appropriate priority of course."

Even though EPs are an excellent technology to enhance resource integration and promote interaction with actors, the exchange is conducted both in virtual and real-world settings by most personal and household-related EPs. E.g. personal services such as relocation assistance must be provided directly on site. However, the EPs we surveyed consider this to be an added value and welcome that actors also get to interact in real life. One interviewee even stated that: "this is what guides us, so we say we don't want to be an online tool that draws people online for its own sake, but rather a platform that is a useful online tool and always results in real added value offline as well".

The interviewed POs consider the actors on the EP the key roles and try to remain in the background during the interaction as much as possible and assist only if needed in the interaction processes. E.g. Nebenan ensured the increase in resource density (i.e. availability of other actors and offerings) at an early platform stage by nudging the actors through displaying ideas for future postings and providing a template that the actors could fill out.

Another key challenge for novel EPs is the initial lack of huge communities and the struggle with balancing provider and user numbers (chicken-and egg-problem). To increase resource density and maintain commitment, a growing number of users increases the attractiveness for both new and established actors. Thus, the EPs try to increase the total number of active actors by connecting to social networks and increasing existing actors' loyalty to the EP. To compensate for an initially small community, platforms (e.g. Sandkasten and MyHelpBuddy) actively engage service providers and other actor groups in areas where users encounter a lack of offerings, connect them to prevent dissatisfaction in early stages and build local or specialized communities manually. The EPs, e.g. MyHammer and Nebenan, also share stories via social media to build trust, inspire new interaction opportunities and attract new users. By that, they aim to increase the interaction level of actors on the EP. Conversely, aggressive online marketing via social media may also danger the EP's attractiveness and credibility while having limited effects on actual quality and interaction density. Therefore, most POs adopted a personal touch to their communication and testimonials as a central part of their social media campaigns. Actors "can communicate via our platform if they like, but they can also communicate outside the platform", as one interviewee states, the interaction among actors is also driven by various chat tools and contact possibilities, thus trying to remain as unrestrictive as possible without jeopardizing pay per use/provisionbased business models.

Since for value co-creation, a mutual benefit for the actors is the key goal, all actors should be able to derive their individual value. In order to be willing to share resources with other actors, rules must be established to ensure that these resources are treated with trust and respect. Many companies, e.g. Nebenan, rely primarily on a netiquette and trust the actors to follow these rules by choice. Additionally, we often found that, e.g. in neighborhood EPs, the actors themselves govern interaction through their own social rules. Implicating that additional monitoring by the PO can be eliminated.

\subsection{Facilitating service innovation}

As markets are continually changing and actor demands increase, EPs must ensure feasible and sustainable service innovation. While the interviewed companies principally claim that service innovations are driven by the users, these are certainly also dependent on monetary resources and development capacities. However, as one interviewee even suggests: "we always have many more ideas and many more plans than we have development resources. Which is a bit good and a bit bad. Because it is bad and developers have become very expensive... conversely, it forces you to prioritize even harder, which is good'. The restrictions make it easier to select which innovations to implement. Regardless of this, there are still functionalities that must be developed due to e.g. data protection issues and do not necessarily ensure all actors' approval. 


\begin{tabular}{|c|c|}
\hline & \\
\hline & $\begin{array}{l}\text { Ease of Entry (1); Mutual Problem and Needs (2); } \\
\text { Co-Creation (3) Service Innovation (4) }\end{array}$ \\
\hline & $\begin{array}{l}\text { - Convey trust through engaging labels, e.g. TÜV tested } \\
(1,4) \\
\text { - Define risk-based pricing and costs collaboratively }(1,2) \\
\text { - Employ rules to prevent misconduct, e.g. netiquette }(1,3) \\
\text { - Provide binding quality standards }(1,2) \\
\text { - Verify actors through legal documents, e.g. ID records } \\
\text { - Use relationships with established companies }(1) \\
\text { - Adopt to market changes quickly, e.g. through agile } \\
\text { development }(2,4) \\
\text { - Share stories via social media }(3) \\
\text { - Add a personal touch to communication and testimonials } \\
\text { - } 3 \text { - Treat all actors as equal partners }(2,4) \\
\text { - Provide opportunities for feedback, e.g. through } \\
\text { feedback systems or hosting exchange rounds }(2,4)\end{array}$ \\
\hline & $\begin{array}{l}\text { - Increase usability/ accessibility through virtual and real- } \\
\text { world components e.g. attending conferences }(1,3,4) \\
\text { - Ensure user competence through, e.g. video tutorials } \\
(1,3,4) \\
\text { - Provide incentives for new users, e.g. welcome packages } \\
\text { (1) } \\
\text { - Identify possible UX-optimization through, e.g. } \\
\text { clickstream data }(2,4) \\
\text { - Involve actors in EP changes }(2,3) \\
\text { - Implement individual solutions for the users, e.g. white } \\
\text { label solutions }(2,4) \\
\text { - Allow exchange of resources in virtual and real-world } \\
\text { settings }(3) \\
\text { - Assist in interaction if necessary, e.g. nudge actors with } \\
\text { ideas to engage }(3) \\
\text { - Anticipate user needs, e.g. participate in trade fairs }(2,4) \\
\text { - Allow rating and endorsement systems }(2,4)\end{array}$ \\
\hline & $\begin{array}{l}\text { - } \text { Connect to social media platforms }(1,3) \\
\text { - Participate in physical events. e.g. host networking } \\
\text { events }(1,3) \\
\text { - Conduct marketing campaigns }(1) \\
\text { - Increase B2B management }(1,4) \\
\text { - Identify market niches, e.g. noticing potential areas with } \\
\text { lack offerings }(1,2,4) \\
\text { - Allow for various use of chat tools }(1,3) \\
\text { - Implement feedback channels prominently }(2,4) \\
\text { - Present impact reports and success stories to show user- } \\
\text { centeredness and innovativeness }(1,4)\end{array}$ \\
\hline
\end{tabular}

Table 2. Mechanisms and activities to build trust commitment and visibility

Furthermore, some companies also argue that users do not know what they wish for before they have it. Therefore, e.g. Animus tries to anticipate the demands of the actors by participating in trade fairs and informing themselves through current literature. Also, our interviewees always try to learn from the actors and adopt new ideas. With enough creative space on the EP, this often leads to the development of new services tailored to the actors' needs. E.g. Nebenan, launched a new subpage by recognizing the needs for yard markets and included it in their service portfolio.

To further facilitate the discovery of new services, the interviewees frequently mentioned that all actors must be treated as equal partners to create an open feedback culture. Candid communication allows for ideas to be addressed and discussed openly. Especially, opportunities to provide user feedback, e.g. through technical implementation, should be created and actively demanded from all actors. This also includes feedback about the usability of the platform, e.g. through bug reports.

Meanwhile, companies, e.g. MyHammer, can afford to have their own $R \& D$ for innovations, e.g. MyFeelix hosts open exchange rounds among their employees, where ideas can be shared. To manage this influx of ideas companies, e.g. Pengueen and Nebenan, rely on agile development methods to increase the speed of implementation and user-centeredness of the usergenerated ideas. As the ideas and wishes of actors sometimes need further investigation, EPs, e.g. Care and Pengueen, conduct user workshops and UX-tests to define novel solutions that surpass the original input and reinvent processes to suit the actor's processes more appropriately. This user proximity, in turn, promotes trust and ensures that concerns can be addressed promptly. As actors always exchange information with each other, e.g. about the satisfaction with the service or the usability of the platform, the special value must be placed on the commitment with the actors. A classic tool to help actors make informed decisions is, of course, a rating or endorsement system, which sometimes, as the case with MyHelpBuddy, asks actors to rate each other. To ensure high-quality services POs, e.g. Einkaufshelden and Yoopies, evaluate samples and accompany actors. Trustworthiness can be further promoted by treating all actors as partners. If the actors trust the company to the extent that they provide their data, targeted offers and improved matchings can be made, from which both sides can benefit.

\section{Discussion}

In this contribution, we provide new insights into EP activities for practitioners looking for descriptive information, and for scholars of the service science and the platform literature, on how to enable and foster interaction on EPs that provide personal services. Thereby, we contribute to existing research gaps concerning a) applicable research that draws from Service Logic [43], the call for actionable information for practitioners designing EPs [5] and c) a lack of research on the digitalization of personal services [27]. 
The interviews' analysis provided further evidence that the provided set of categories provide a suitable conceptual framework to depict key activities and mechanisms to enable and foster interaction on EPs. We evaluated this through deductive and inductive coding and found three fundamental elements that motivated POs to design and improve EP features: trust, commitment, and visibility. The intent to improve and nurture these three aspects to attract and bind more actors is similarly observable in all four categories, i.e. easing the entry, identifying mutual problems and needs, supporting value co-creation and fostering service innovation. While trust, commitment and visibility are widely discussed as sub-concepts of customer or media engagement in marketing literature [9], our preceding literature analysis found that these concepts are not explicitly discussed in design principles for EPs, e.g. [4, 5]. We thus argue that the combination of engagement literature and the generation of design knowledge for EPs should be considered more thoroughly since the focus of EPs is literally on actor engagement. Further, customer engagement provides a promising lens to conceptualize "a motivational state that occurs by virtue of interactive co-creative, customer experiences with a focal agent/object (e.g. a brand) in focal service relationships" [10] p. 259.

A wide range of relational antecedents and consequences are considered in current discourses of different conceptualizations of customer engagement. While the importance and effect of the concepts trust, visibility and commitment have been discussed in EP research (e.g. [7, 9]), a comprehensive set of supporting activities yet remains to be specified. By providing an initial set of activities from the personal service context, this research considers trust, i.e. a prerequisite of the relationship quality [26], visibility, i.e. the perception of other actors, available information as well as opportunities and needs [22, 39], and commitment, i.e. the desire to maintain the relationship [26] to be concrete and pervasive motivators for POs to foster the ease of entry, identifying mutual problem and needs, co-creation and service innovation.

In our results, key challenges of EPs and platform literature are reflected. While e.g. multihoming is not mentioned as a major concern by the interviewees, the chicken-egg-problem, the level of governess and openness are frequently addressed. POs e.g. try to address the chicken-egg-problem by using/providing core services with their own employees, attracting business partners that bring their respective network onto the EP and/or provide services of high standard and volume to other actors or manually searching and connecting demand and offers if no suitable match is available. This is in line with Veisdal [44], who depicts such activities as suitable mechanisms to circumvent an initial lack of participants on one or multiple sides of the market.

While the availability and successful matching of resources on the EP is central to its success [34], initially, the EP has to earn the trust of actors through activities prior to the actual co-creation of value [30]. In our sample, trust is often established at an early stage through personal contact among PO and users and can, later on, be supported or fully replaced by testimonials or reviews, after an appropriate number of actors has been reached. Especially success stories from other actors can thereby provide the social proof needed, in order to build a trusting environment [30]. Additionally, the interviewed companies, rely on user authentication and, in some cases, even demand personal identity cards or business register entries to ensure a favorable trade-off of quality and quantity. This is especially the case when one or multiple sides of the market are growing fast and are expected to diminish the average service quality on the EP. This is in line with [44], who also report that a vast selection of e.g. suppliers might lead to higher searching costs of actors. While these findings seem to be applicable to EPs in general, the POs in our sample often rely on a mixed virtual and real-world approach regarding the onboarding and co-creation process. This physical component is reflected fittingly in the EP perspective that assumes physical touchpoints as integral factors of interaction between actors [9].

Service Logic depicts all actors as resource integrators [21] hence EP should deliberately ease and improve the individual resource integration abilities of all actors e.g. by appropriately handling data [37], in order to contribute to the well-being of all actors in the service ecosystem [29]. As data offers a wide array of utilities for personalization on the EPs, we were surprised by the lack of automated personalization features on the EPs, despite its potential to foster commitment [6]. Therefore, we argue that there is still room for improvement. Autonomy, competence, physical relatedness, the three components of selfdetermination theory, positively impact the motivation and commitment in a digital environment [33]. We argue that more attention needs to be paid on how to engage the actors to stimulate these needs. In line with, e.g. [37], we propose that these needs and motivational aspects as autonomy and personalization are taken into account, when defining design principles for EPs.

Based on the results of the personal services sector, we argue that the majority of presented activities and mechanisms can also be used in other sectors, as the involvement of actors plays a central role in all service ecosystems [29] and thus, as 
illustrated, core activities and mechanisms can be applied in a similar way in other sectors.

\section{Conclusion, limitations \& outlook}

EPs are increasingly popular and powerful means to enable co-creation and service innovation. Therefore, the optimal design of these platforms is receiving growing attention in research and practice. In this study, we, therefore, conducted expert interviews with founders, CEOs, and managers of 14 EP companies from the personal and householdrelated service sector, to gain insights into essential success factors as well as related activities and mechanisms. To analyze the interviews, we employed deductive and inductive coding, and were able to solidify the validity of four categories for EP design that we derived in a preceding literature review: (1) easing the entry, (2) identifying mutual problems and needs, (3) supporting value co-creation, and (4) facilitating service innovation. We found that these design categories have three elements that motivate POs to implement activities and mechanisms: trust, commitment, and visibility. Further, we identified a total of 29 activities and mechanisms to build trust, increase actor commitment and increase visibility on EPs.

Based on these empirical insights scholars and practitioners may derive design principles and redefine their activities to build and foster interaction on EPs. Even though we are confident that the results of this study support the endeavors of practitioners, as well as provide new theoretical insights, we have to make a few limitations. As we limited the interview sample to experts from the DACH-region and the sector of personal services, we may only argue that our findings must be compared to other EPs. Also, resulting from the deliberate choice to interview experts in the $\mathrm{B} 2 \mathrm{C}$ sector we refrained from interviewing consumers as the selection of experts for our interviews was more robustly ensured by relying on established and measurable criteria such as job position and time in the market. This being said, future research should extend this study by considering a multi-perspective that actively seeks to balance the interests of different actors and/or identifying similarities and differences to other sectors.

\section{Acknowledgments}

This paper is part of the project "Begleitforschung Personennahe Dienstleistungen" (BeDien), funded by the German Federal Ministry of Education and
Research (BMBF), grant number 02K17A080 and 81.

\section{References}

[1] Alt, R., "Evolution and perspectives of electronic markets", Electronic Markets 30(1), 2020, pp. 1-13.

[2] Aulkemeier, F., M.-E. Iacob, and J. van Hillegersberg, "Platform-based collaboration in digital ecosystems", Electronic Markets 29(4), 2019, pp. 597-608.

[3] Barrett, M., E. Davidson, University of Hawai'i at Mãnoa, J. Prabhu, University of Cambridge, and S.L. Vargo, "Service Innovation in the Digital Age: Key Contributions and Future Directions", MIS Quarterly 39(1), 2015, pp. 135-154.

[4] Bidar, R., J. Watson, and A. Barros, "Literature review to determine environmental and cognitive factors underlying user value cocreation behaviour", PACIS 2016 Proceedings, 2016.

[5] Blaschke, M., U. Riss, K. Haki, and S. Aier, "Design principles for digital value co-creation networks: a service-dominant logic perspective", Electronic Markets 29(3), 2019, pp. 443-472.

[6] Blasco-Arcas, L., B.I. Hernandez-Ortega, and J. Jimenez-Martinez, "Engagement platforms: The role of emotions in fostering customer engagement and brand image in interactive media", Journal of Service Theory and Practice 26(5), 2016, pp. 559-589.

[7] Breidbach, C.F., and R.J. Brodie, "Engagement platforms in the sharing economy: Conceptual foundations and research directions", Journal of Service Theory and Practice 27(4), 2017, pp. 761-777.

[8] Breidbach, C.F., J.D. Chandler, and P.P. Maglio, "The Duality of Second Screens: A Phenomenological Study of Multi-platform Engagement and Service Experiences", 2015 48th Hawaii International Conference on System Sciences, IEEE 2015, 14321441.

[9] Breidbach, F. Christoph, C., R. Brodie, and L. Hollebeek, "Beyond virtuality: from engagement platforms to engagement ecosystems", Managing Service Quality: An International Journal 24(6), 2014, pp. 592-611.

[10] Brodie, R.J., L.D. Hollebeek, B. Jurić, and A. Ilić, "Customer Engagement: Conceptual Domain, Fundamental Propositions, and Implications for Research", Journal of Service Research 14(3), 2011, pp. 252-271.

[11] Chesbrough, H.W., Open innovation: the new imperative for creating and profiting from technology, Harvard Business School Press, Boston, Mass, 2003.

[12] Cusumano, M.A., A. Gawer, and D.B. Yoffie, The Business of Platforms: Strategy in the Age of Digital Competition, Innovation, and Power, Harper Business, 2019.

[13] Deci, E.L., and R.M. Ryan, Handbook of selfdetermination research, University of Rochester Press, Rochester, NY, US, 2002.

[14] Edvardsson, B., B. Tronvoll, and T. Gruber, "Expanding understanding of service exchange and value co-creation: a social construction approach", 
Journal of the Academy of Marketing Science 39(2), 2011, pp. 327-339.

[15] Fischer, S., L. Lohrenz, C. Lattemann, and S. RobraBissantz "Critical Design Factors for Digital Service Platforms: A Literature Review", Proceedings of the European Conference of Information Systems (ECIS), 2020.

[16] Fischer, S., A. Lux, R. Guerrero, R. Ahmad, L. Lohrenz, and C. Lattemann, "Digitalisierung als Grundlage wertvoller Zusammenarbeit - Die Gestaltung von Service-Ökosystemen in den personennahen Dienstleistungen", HMD Praxis der Wirtschaftsinformatik, 2020.

[17] Frow, P., S. Nenonen, A. Payne, and K. Storbacka, "Managing Co-creation Design: A Strategic Approach to Innovation", British Journal of Management 26(3), 2015, pp. 463-483.

[18] Fu, W., Q. Wang, and X. Zhao, "Platform-based service innovation and system design: a literature review", Industrial Management \& Data Systems 118(5), 2018, pp. 946-974.

[19] Gawer, A., and M.A. Cusumano, "Industry Platforms and Ecosystem Innovation: Platforms and Innovation", Journal of Product Innovation Management 31(3), 2014, pp. 417-433.

[20] Göbel, H., and S. Cronholm, "Nascent Design Principles Enabling Digital Service Platforms", In J. Parsons, T. Tuunanen, J. Venable, B. Donnellan, M. Helfert and J. Kenneally, eds., Lecture Notes in Computer Science. Springer International Publishing, Cham, 2016, 52-67.

[21] Grönroos, C., "Value co-creation in service logic: A critical analysis", Marketing Theory 11(3), 2011, pp. 279-301.

[22] Grotherr, C., M. Semmann, and T. Böhmann, "Grotherr et al. 2018 Engaging Users to Co-create.pdf", Proceedings of the 51st Hawaii International Conference on System Sciences, 2018.

[23] Hein, A., M. Böhm, and H. Krcmar, "Digitale Plattformen", In M.H. Dahm and S. Thode, eds., Strategie und Transformation im digitalen Zeitalter. Springer Fachmedien Wiesbaden, Wiesbaden, 2019, 181-199.

[24] Hein, A., M. Schreieck, T. Riasanow, et al., "Digital platform ecosystems", Electronic Markets 30(1), 2020, pp. 87-98.

[25] Heinonen, K., T. Strandvik, K.-J. Mickelsson, B. Edvardsson, E. Sundström, and P. Andersson, "A customer-dominant logic of service", Journal of Service Management 21(4), 2010, pp. 531-548.

[26] Hollebeek, L.D., "Demystifying customer brand engagement: Exploring the loyalty nexus", Journal of Marketing Management 27(7-8), 2011, pp. 785-807.

[27] Lattemann, C., S. Robra-Bissantz, and C. Ziegler, "Die Komposition personennaher Dienstleistungen von morgen", HMD Praxis der Wirtschaftsinformatik, 2020.

[28] Lattemann C, Robra-Bissantz S (2006) Customer Governance - IC Based Concepts for a Successful Customer Integration. In: Hannula M, Järvelin A-M, Seppä M. (eds) Frontiers of e-Business Research.
[29] Lusch, R.F., and S. Nambisan, "Service Innovation: A Service-Dominant Logic Perspective", MIS Quarterly 39(1), 2015, pp. 155-175.

[30] Oh, S., and J.Y. Moon, "Calling for a shared understanding of the 'sharing economy", Proceedings of the 18th Annual International Conference on Electronic Commerce: e-Commerce in Smart connected World, Association for Computing Machinery (2016), pp. 1-5.

[31] Ojasalo, J., and K. Ojasalo, "Service Logic Business Model Canvas", Journal of Research in Marketing and Entrepreneurship 20(1), 2018, pp. 70-98.

[32] Ordanini, A., and A. Parasuraman, "Service Innovation Viewed Through a Service-Dominant Logic Lens: A Conceptual Framework and Empirical Analysis", Journal of Service Research 14(1), 2011, pp. 3-23.

[33] Peters, D., R.A. Calvo, and R.M. Ryan, "Designing for Motivation, Engagement and Wellbeing in Digital Experience", Frontiers in Psychology 9, 2018.

[34] de Reuver, M., C. Sørensen, and R.C. Basole, "The Digital Platform: A Research Agenda", Journal of Information Technology 33(2), 2018, pp. 124-135.

[35] Saldaña, J., The coding manual for qualitative researchers, Sage, Los Angeles, Calif, 2009.

[36] Schreieck, M., M. Wiesche, and H. Krcmar, "Design and Governance of Platform Ecosystems - Key Concepts and Issues for Future Research", Proceedings of the Twenty-Fourth European Conference on Information Systems (ECIS), 2016, pp. 1-20.

[37] Semmann, M., and C. Grotherr, "How to Empower Users for Co-Creation - Conceptualizing an Engagement Platform for Benefits Realization", Proceedings der 13. Internationalen Tagung Wirtschaftsinformatik (WI 2017), 2017, pp. 91-105.

[38] Skjott Linneberg, M., and S. Korsgaard, "Coding qualitative data: a synthesis guiding the novice", Qualitative Research Journal 19(3), 2019, pp. 259270.

[39] Spagnoletti, P., A. Resca, and G. Lee, "A Design Theory for Digital Platforms Supporting Online Communities: A Multiple Case Study", Journal of Information Technology 30(4), 2015, pp. 364-380.

[40] Tiwana, A., Platform Ecosystems: Aligning Architecture, Governance, and Strategy, Newnes, 2013.

[41] Tiwana, A., B. Konsynski, and A.A. Bush, "Platform Evolution: Coevolution of Platform Architecture, Governance, and Environmental Dynamics", Information Systems Research 21(4), 2010, pp. 675687.

[42] Vargo, S.L., and R.F. Lusch, "Evolving to a New Dominant Logic for Marketing”, Journal of Marketing 68(1), 2004, pp. 1-17.

[43] Vargo, S.L., and R.F. Lusch, "Service-dominant logic 2025", International Journal of Research in Marketing 34(1), 2017, pp. 46-67.

[44] Veisdal, J., "The dynamics of entry for digital platforms in two-sided markets: a multi-case study", Electronic Markets 30(3), 2020, pp. 539-556. 